\title{
DEXMEDETOMEDINE-KETAMINE VERSUS PROPOFOL-KETAMINE AS ANAESTHETIC AGENTS IN PAEDIATRIC CARDIAC CATHETERIZATION
}

\author{
Ali NP ${ }^{1}$, Kanchi $\mathrm{M}^{2}$, Singh $\mathrm{S}^{3}$, Prasad $\mathrm{A}^{4}$, Kanase $\mathrm{N}^{5}$
}

\begin{abstract}
Introduction: Anaesthesia for these patients undergoing for interventional procedures in paediatric patients with congenital cardiac anomalies remains a challenge for the anaesthesiologist. There are no specific techniques to follow and anaesthetic procedure is modified according to the cardiac anomalies, clinical condition of the patients and the cardiologist's requirements. Basically the anaesthesiologist can either provide sedation or general anaesthesia.
\end{abstract}

Objective: The aim of this study was to compare the sedation level, haemodynamic effects and recovery patterns in paediatric patients undergoing sedation for cardiac catheterization either with dexmedetomidine-ketamine or propofol-ketamine combination.

Materials \& Methods: Sixty patients between the ages of 1 to 12 years were scheduled for cardiac catheterization at Cardiac Catheterization Laboratory of Narayana Hrudayalaya Institute of Medical Sciences, Bangalore, India for a period of six months (April to September 2012) for evaluation and intervention of congenital heart disease. Patients were randomly divided into 2 groups of 30 each. All patients were premedicated with intravenous midazolam $(0.05 \mathrm{mg} / \mathrm{kg}$ upto $2 \mathrm{mg})$ and glycopyrrolate $(10 \mu \mathrm{g} / \mathrm{kg}) 5$ minutes before the procedure and anaesthesia was induced with ketamine $1 \mathrm{mg} / \mathrm{kg}$. The dexmedetomidine-ketamine group (group $\mathrm{D}, \mathrm{n}=30$ ), received dexmedetomidine $1 \mu \mathrm{g} / \mathrm{kg}$ over 10 minutes.
Propfol-ketamine group (group $\mathrm{P}, \mathrm{n}=30$ ) received $50 \mu \mathrm{g} / \mathrm{kg} / \mathrm{min}$ of propofol by infusion. Heart rate $(\mathrm{HR})$, Systolic Blood Pressure ( SBP), Diastolic Blood Pressure (DBP), Mean Arterial Pressure (MAP), peripheral oxygen saturation $\left(\mathrm{SpO}_{2}\right)$, respiratory rate $(R R)$, and modified Steward score of all patients was recorded at baseline, after induction and every 10 minutes thereafter. The time to reach a modified Steward score of $>0 r=6$ was recorded.

Results: Recovery time was significantly less in group $P$ (mean $39 \pm 12.32$ mins) than in group $D$ (mean 48 $\pm 15.15 \mathrm{mins}$ ). Statistical significant difference $(p<0.05)$ was found between group $D$ and $\mathrm{P}$ regarding systolic blood pressure (64.48 \pm $11.21 \mathrm{mmHg}$ vs $56.06 \pm 10.13 \mathrm{mmHg}$ ), diastolic blood pressure $(40.08 \pm 8.00 \mathrm{mmHg}$ vs $35.05 \pm$ $6.64 \mathrm{mmHg})$ and mean arterial pressure $(48.32 \pm$ $8.34 \mathrm{mmHg}$ vs $42.39 \pm 7.98 \mathrm{mmHg}$ ). For maintenance less additional ketamine was required in group $D(22.76 \pm 11.87 \mathrm{mg})$ than group $P$ $(25.10 \pm 20.73 \mathrm{mg})$ but this was not statistically significant.

Conclusion: Clinical outcome of both groups was similar and there was no significant difference in the recovery patterns and haemodynamic status and hence it is concluded that either of the techniques is suitable for children undergoing catheterization and interventional procedures.

Key-words: Dexmedetomidine, Propfol-ketamine, sedation level, haemodynamic effects.

1. Lt Col Nadeem Parvez Ali, MBBS, DA, FCPS (Anaesthesiology), Classified Spl in Anaesthesiology, Department of Anaesthesia \& Intensive Care, CMH, Dhaka; 2. Dr Muralidhar Kanchi, MBBS, MD (Anaesthesiology), FICA, MBA, HOD, Department of Cardiac Anaesthesia, Narayana Hrudayalaya Institute of Medical Sciences, Bangalore, India; 3. Dr Sanjeev Singh, MBBS, DA, MD (Anaesthesiology), FCA, Department of Anaesthesia and Intensive Care, School of Medical Sciences, College of Health Sciences, Kwame Nkrumah University of Science and Technology, Kumasi, Ghana, West Africa; 4. Dr Apoorva Prasad, MBBS, MD (Anaesthesiology), Consultant, Department of Cardiac Anaesthesia, Narayana Hrudayalaya Institute of Medical Sciences, Bangalore, India; 5. Dr Naseema Kanase, MBBS, MD (Anaesthesiology), Assoc Prof, Karad Institute of Medical Sciences, Karad, India. 


\section{Introduction}

Paediatric cardiac catheterizations have increased exponentially in recent years. Anaesthesia for these patients undergoing for interventional procedures such as patent ductus arteriosus, atrial septal defects, ventricular septal defects, collateral vessels, valve stenosis, vessel stenosis, and conduction abnormalities remains a challenge for the anaesthesiologist. Problems faced in the catheterization laboratory include unfamiliar environment compared to operation theatre, difficult access to the patient and risks of radiation. The goals of the anaesthetic management during cardiac catheterization are adequate analgesia, sedation, immobility, and cardiovascular stability ${ }^{1}$. Various drugs such as ketamine, dexmedetomidine, propofol, and combinations of drugs have been used with variable degrees of success ${ }^{2-5}$. There are no specific techniques to follow and anaesthetic procedure is modified according to the cardiac anomalies, clinical condition of the patients and the cardiologist's requirements. Basically the anaesthesiologist can either provide sedation or general anaesthesia. Jobeir et al. suggested that the administration of ketamine and midazolam or their combination in small doses during cardiac catheterization in children is safe ${ }^{6}$. Bernard et al. found propofol associated with profound respiratory depression with fairly narrow therapeutic window as well as metabolic acidosis following short-term propofol infusion may be an early warning of propofol infusion syndrome. In 2001, the FDA issued a black box warning which reported the results of a study on a fair number of sedated patients in paediatric intensive care units treated with either propofol or standard sedative agents. In that unpublished study, a significantly higher number of paediatric patients died due to propofol $^{7}$. Kogan et al. reported propofol-ketamine combination as a feasible option in spontaneously breathing children presenting for cardiac catheterization procedure ${ }^{8}$. Ketamine and propofol have opposing influences on blood pressure, heart rate, Systemic Vascular Resistance and preserve respiratory function. The aim of this study was to compare the sedation level, haemodynamic effects and recovery patterns in paediatric patients undergoing sedation for cardiac catheterization either with dexmedetomidine-ketamine or propofol -ketamine combination.

\section{Materials \& Methods}

This study was conducted in the Cardiac Catheterization Laboratory of Narayana Hrudayalaya Institute of Medical Sciences, Bangalore, India for a period of six months (April to September 2012). After ethical committee approval and written consent from the parents, 60 patients in the age group of 1 to $12 \mathrm{yrs}$ scheduled for cardiac catheterization for evaluation and intervention of congenital heart disease were randomly divided into 2 groups of 30 each using closed envelope method. Group D underwent sedation with dexmedetomidine-ketamine combination. One case had to be abandoned due to brady-arrhythmia induced during catheterization procedure. Group P was sedated with propofol-ketamine combination. Patients requiring mechanical ventilation, intravenous inotropic support were excluded from the study. After minimum fasting of $2 \mathrm{hrs}$ for clear water, $4 \mathrm{hrs}$ for milk and 6 hrs for solid food, an IV line was established and $0.45 \% \mathrm{NaCl}$ solution was started at a rate of $100 \mathrm{ml} / \mathrm{kg} / 24 \mathrm{hrs}$. All patients were premedicated with intravenous midazolam $(0.05 \mathrm{mg} / \mathrm{kg}$ upto $2 \mathrm{mg})$ and glycopyrrolate $(10 \mu \mathrm{g} / \mathrm{kg}) 5$ minutes before the procedure. Upon arrival in the catheterization laboratory, the heart rate (HR), Systolic Blood Pressure (SBP), Diastolic Blood Pressure (DBP), Mean Arterial Pressure (MAP), peripheral oxygen saturation $\left(\mathrm{SpO}_{2}\right)$, respiratory rate $(\mathrm{RR})$ and modified Steward Score of all patients was recorded at baseline, after induction and every 10 minutes thereafter in both groups, patients were induced with ketamine $1 \mathrm{mg} / \mathrm{kg}$ in bolus. Thereafter, group $D$ patients received dexmedetomidine $1 \mu \mathrm{g} / \mathrm{kg}$ over 10 mins. Group P patients received $50 \mu \mathrm{g} / \mathrm{kg} / \mathrm{min}$ of propofol by infusion. Additional doses of ketamine $1 \mathrm{mg} / \mathrm{kg}$ were administered depending on the clinical requirement in both groups. Supplemental oxygen at 3-4 L/min was given via face mask to all the patients. Recovery time, the primary outcome, were evaluated by a modified Steward score $(\text { Table-I })^{9}$. A score of $>0 r=6$ meant that the patient was awake or responded to verbal stimuli, had purposeful motor activity, and coughed on command. The time to reach a modified Steward score of $>0 r=6$ was recorded. Hypotension was defined when the systolic blood pressure decreased by $20 \%$ from the baseline ${ }^{10}$. 
Table-I: Recovery scoring system (Modified from Steward).

\begin{tabular}{|l|l|l|}
\hline \multirow{4}{*}{ Consciousness } & Awake & 3 \\
\cline { 2 - 3 } & Responds to verbal stimuli & 2 \\
\cline { 2 - 3 } & Responds to tactile stimuli & 1 \\
\cline { 2 - 3 } Airway & Not responding & 0 \\
\hline \multirow{3}{*}{ Motor } & Cough on command or cry & 2 \\
\cline { 2 - 3 } & Maintains good airway & 1 \\
\cline { 2 - 3 } & Requires airway assistance & 0 \\
\hline & Moves limbs purposefully & 2 \\
\cline { 2 - 3 } & Nonpurposeful movement & 1 \\
\cline { 2 - 3 } & Not moving & 0 \\
\hline
\end{tabular}

\section{Statistical analysis}

All data (patient's gender, age, weight, HR, SBP, $\mathrm{DBP}, \mathrm{MAP}, \mathrm{SpO}_{2}, \mathrm{RR}$, and modified Steward Score for both groups) were analyzed using SPSS software version 12.0 (Statistical Packages for the Social Sciences, Chicago, IL, USA). Linear variable was expressed as mean \pm standard error of the mean and compared using Student's $t$ test. A two tailed $\mathrm{p}<0.05$ was considered as statistically significant.

\section{Results}

The demographic characteristics of each group as shown in Table-II. From 59 patients who met the inclusion criteria for enrollment into this study, 56\% were female and $44 \%$ were male. Mean age of the patients was 4.4 years (range 1-12 years). Mean weight of the patients was $14.2 \mathrm{~kg}$ (range 5.5-50 $\mathrm{kg}$ ). There were no statistically significant differences between the groups with respect to age, weight \& sex (Table-II).

Table-II: Demographic data.

\begin{tabular}{|l|l|l|c|}
\hline Parameters & Group D & Group P & p value \\
\hline Age (years) & $4.3( \pm 3.0)$ & $4.5( \pm 3.3)$ & NS \\
\hline Weight (Kg) & $13.1( \pm 5.5)$ & $15.4( \pm 9.7)$ & NS \\
\hline Gender Male/Female & $14 / 15$ & $12 / 18$ & NS \\
\hline \multicolumn{4}{|c|}{ NS - Not Significant } \\
\hline
\end{tabular}

Diagnostic procedures were performed in 22 patients (13 in group D, 9 in group P). Interventional procedures, such as atrial septal defect, ventricular septal defect, patent ductus arteriosus device closures, balloon pulmonary valvulotomy and coarctoplasty were performed in 37 patients (16 in group D, 21 in group P) (Table-III).
Table-III: Procedures performed for different congenital cardiac anomalies in each group.

\begin{tabular}{|c|c|c|c|}
\hline Procedure & $\begin{array}{c}\text { Group-D } \\
(n=29)\end{array}$ & $\begin{array}{l}\text { Group-P } \\
(n=30)\end{array}$ & Total \\
\hline Diagnostic & 13 & 9 & 22 \\
\hline \multicolumn{4}{|l|}{ Interventional } \\
\hline $\begin{array}{l}\text { Atrial Septal Defect (ASD) } \\
\text { device closure }\end{array}$ & 3 & 8 & 11 \\
\hline $\begin{array}{l}\text { Ventricular Septal Defect } \\
\text { (VSD) device closure }\end{array}$ & 2 & 2 & 4 \\
\hline $\begin{array}{l}\text { Patent Ductus Arteriosus } \\
\text { (PDA) device closure }\end{array}$ & 9 & 7 & 16 \\
\hline $\begin{array}{l}\text { Balloon Pulmonary } \\
\text { Valvuloplasty (BPV) }\end{array}$ & 1 & 2 & 3 \\
\hline \multirow[t]{3}{*}{ Coarctoplasty } & 1 & 2 & \begin{tabular}{l|l}
3 &
\end{tabular} \\
\hline & 16 & 21 & 37 \\
\hline & & & 59 \\
\hline
\end{tabular}

Recovery time, as assessed by modified Steward Score was lower in group P $(39 \pm 12.32 \mathrm{~min})$ than in group D $(48 \pm 15.15 \mathrm{~min})$ which was significant (Fig-1). There were no significant differences in terms of $H R$, and $R R$. Statistical significant difference $(p<0.05)$ was found between group $D$ and $P$ regarding SBP $(64.48 \pm 11.21 \mathrm{mmHg}$ vs $56.06 \pm$ $10.13 \mathrm{mmHg})$, DBP $(40.08 \pm 8.00 \mathrm{mmHg}$ vs $35.05 \pm$ $6.64 \mathrm{mmHg})$ and MAP $(48.32 \pm 8.34 \mathrm{mmHg}$ vs 42.39 $\pm 7.98 \mathrm{mmHg}$ ) (Table-IV).

Table-IV: Comparison between two groups with different variables.

\begin{tabular}{|l|c|c|c|}
\hline Parameters & Group $\mathbf{D}(\mathbf{n}=\mathbf{2 9})$ & Group $\mathbf{P}(\mathbf{n}=\mathbf{3 0})$ & P-value \\
\hline Heart Rate (per min) & $70.69 \pm 16.56$ & $66.61 \pm 11.92$ & NS \\
\hline Systolic Blood Pressure $(\mathrm{mmHg})$ & $64.48 \pm 11.21$ & $56.06 \pm 10.13$ & $\mathrm{p}<0.05$ \\
\hline Diastolic Blood Pressure $(\mathrm{mmHg})$ & $40.08 \pm 8.00$ & $35.05 \pm 6.64$ & $\mathrm{p}<0.05$ \\
\hline Mean Arterial Pressure $(\mathrm{mmHg})$ & $48.32 \pm 8.34$ & $42.39 \pm 7.98$ & $\mathrm{p}<0.05$ \\
\hline $\mathrm{SPO}_{2}$ (Oxygen saturation) & $63.69 \pm 12.73$ & $58.00 \pm 9.79$ & $\mathrm{NS}$ \\
\hline Respiratory Rate (per min) & $15.40 \pm 3.38$ & $14.21 \pm 2.49$ & $\mathrm{NS}$ \\
\hline Steward Score & $1.00 \pm 0.17$ & $1.05 \pm 0.26$ & NS \\
\hline \multicolumn{4}{|l|}{ Data were presented as mean $\pm \mathrm{SD}$, Statistical significant difference $(\mathrm{p}<0.05)$, NS - Not Significant } \\
\hline
\end{tabular}

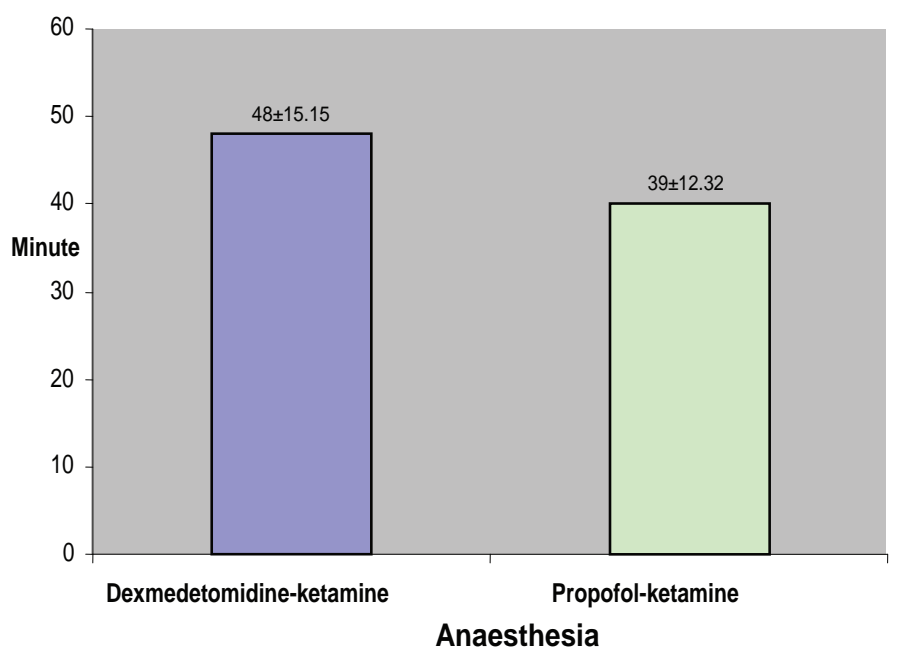


There was no significant difference in terms of sedation scores between the groups. Less additional ketamine for maintenance was required in group D $(22.76 \pm 11.87 \mathrm{mg})$ than group $P$ $(25.10 \pm 20.73 \mathrm{mg})$ but was not significant. Complications were encountered in 12 patients. One patient in the Dexmedetomidine group developed brady-arrhythmia during manipulation of the cardiac catheter and the case was excluded from the study. In the other 11 cases, all developed hypotension ( $>20 \%$ decrease from the baseline BP) during the procedure. Seven of these were in the propofol group and 4 in the dexmedetomidine group.

\section{Discussion}

The present study was undertaken with the aim to compare the recovery patterns and haemodynamic effects in spontaneously breathing paediatric patients under sedation, undergoing cardiac catheterization. The two comparative groups were sedated with a combination of dexmedetomidine-ketamine and propofol-ketamine. Ketamine has been well studied for paediatric cardiac catheterization, and it is a safe anaesthetic agent in patients with pulmonary artery hypertension, despite its controversial effects on pulmonary vascular resistance. Low-dose ketamine has been combined with propofol to achieve a synergistic action in paediatric catheterization ${ }^{11}$. It was originally hoped that ketamine would be used as a sole agent for anaesthesia, inducing analgesia, amnesia, loss of consciousness, and immobility. However, because of its adverse psychological effects and the availability of other induction agents, its use diminished rapidly. Emergence reactions in children are less intense, so it can be used for both sedation and general anaesthesia in procedures such as cardiac catheterization (with caution in patients with raised pulmonary vascular resistance $)^{12}$. Singh et al. described use of ketamine as a simple, safe, and effective method for anaesthetizing children in the cardiac catheterization laboratory for interventional procedures $^{13}$. Slonim et al. concluded that, paediatric anaesthesia and sedation, using ketamine and midazolam, can be performed in a designated monitored setting, outside of the operating room, by experienced personnel, including non-paediatricians ${ }^{14}$.
Propofol has been recommended for paediatric cardiac catheterization because of the rapid emergence it produces ${ }^{5}$. However, propofol also has potential disadvantages including a lack of analgesia at subanaesthetic plasma concentrations leading to respiratory depression and decreasing myocardial contractility ${ }^{15}$. Wheeler et al. reported that propofol could be safely and effectively administered at a rate of $179 \mu \mathrm{g} / \mathrm{kg} / \mathrm{min}$ in diagnostic and therapeutic procedures outside the operating room setting ${ }^{16}$. Gozal et al. studied the effects of propofol on the systemic and pulmonary circulations in paediatric patients scheduled for cardiac catheterization ${ }^{17}$. They reported that propofol seemed to be an adequate sedative agent for paediatric patients undergoing cardiac catheterization, including those with intracardiac shunts. Kogan et al. concluded that total intravenous anesthesia with the propofol-ketamine mixture appeared to be a feasible option in spontaneously breathing children presenting for cardiac catheterization ${ }^{8}$. Miner et al. detected a higher rate of subclinical respiratory depression in patients in the ketamine group than the propofol group $^{18}$. There was no difference in the rate of clinical interventions related to respiratory depression, pain, or recall of the procedure between the groups. Recovery agitation was seen more frequently in patients receiving ketamine than in those receiving propofol. The time to regain baseline mental status was longer in the ketamine group than the propofol group. This study suggests that the use of either ketamine or propofol is safe and effective for procedural sedation in the emergency department. Dexmedetomidine is a selective alpha ${ }_{2}$ - adrenergic agonist. It has activity at a variety of locations throughout the central nervous system. Stimulation of alpha $_{2}$ - adrenergic receptors at this site reduces central sympathetic output, resulting in increased firing of inhibitory neurons. The presence of dexmedetomidine at alpha $_{2}$-adrenergic receptors in the dorsal horn of the spinal cord modulates release of substance $P$ and produces its analgesic effects ${ }^{19}$. It has a short half-life of 1.5-3 hours after IV dosing and has significant advantages as a procedural sedative ${ }^{20,21}$. Its limited effect on respiratory drive and its relatively short half-life make it a useful tool for the management of paediatric patients. Dexmedetomidine offers an additional choice for the sedation of children receiving mechanical ventilation in the intensive care 
setting or requiring procedural sedation. Marcia L. Buck et al. concluded in their study that dexmedetomidine is well tolerated when used at recommended doses; it has the potential to cause hypotension and bradycardia and requires close monitoring ${ }^{22}$. In the present study a combination of dexmedetomedine-ketamine was compared with a combination of propofol and ketamine. The results showed that there were significant statistical differences in systolic, diastolic, and mean arterial blood pressures. The systolic, diastolic and mean arterial blood pressures were maintained at a lower level in group P compared to group D. However, the difference in blood pressure did not affect the clinical outcome in either of the groups. There were no significant differences in terms of heart rate, respiratory rate $\& \mathrm{SPO}_{2}$. In a similar study conducted by Zeynep Tosun et al. showed no significant differences in blood pressure, $\mathrm{SPO}_{2}$ and respiratory rate ${ }^{1}$. They found heart rates to be significantly lower in the dexmedetomedine-ketamine group. In their study, patients received a maintenance dose of dexmedetomedine $(0.7 \mathrm{ug} / \mathrm{kg} / \mathrm{min})$ and ketamine $(1 \mathrm{mg} / \mathrm{kg} / \mathrm{min})$ throughout the procedure. The propofol group was given double the dose of propofol (100ug/kg/min) compared to this study group. Recovery time, as assessed by modified Steward Score was longer in dexmedetomidine group $(48 \pm 15.15 \mathrm{~min})$ than in propofol group $(39 \pm 12.32 \mathrm{~min})$ which was significant. They concluded that the recovery time was markedly longer in the dexmedetomidine group compared to the propofol group. In this study, all patients required top-up doses of ketamine for maintenance of sedation. The total dosage of additional ketamine was not significantly different in either of the groups. In the study conducted by Zeynep Tosun et al., ketamine consumption was more in the dexmeditomedine group and maintenance dose of ketamine was continued throughout the procedure ${ }^{1}$. In our study hypotension was encountered in 11 cases, 7 (out of 30 ) in the propofol and 4 (out of 29) in the dexmedetomidine group. Zeynep Tosun et al. had hypotension in 8 (out of 22) in the propofol group compared to 3 (out of 22) patients in dexmeditomedine group ${ }^{1}$. Lebovic et al. compared the effects of ketamine and propofol in pediatric cardiac catheterization and reported that the incidence of patients with hypotension was higher in the propofol group than the ketamine group $(70 \%$ vs $10 \%$, respectively) $)^{23}$.
Kogan et al. reported hypotension in $6.7 \%$ of patients with a propofol plus ketamine combination ${ }^{8}$. Our results corroborate with the results of previous workers. The limitations of this study were that both diagnostic and interventional procedures were taken under consideration. There were a number of cyanotic patients in the diagnostic group which might have affected the mean oxygen saturations and results. The second limitation was a wide range in age and weight of the patients.

\section{Conclusion}

Despite a significant difference in blood pressure between the two groups the clinical outcome was similar. The recovery time was significantly greater in the dexmedetomidine group. Based on the findings it is concluded that either of the techniques is suitable undergoing cardiac catheterization under sedation.

\section{References}

1. Tosun Z, Akin A, Guler G, Esmaoglu A, Boyaci A. Comparison of recovery patterns in dexmedetomidine-ketamine and propofol-ketamine combinations for anesthesia in spontaneously breathing pediatric patients undergoing cardiac catheterization / interventional procedures: Journal of cardiothoracic and Vascular Anesthesia.2006; 20: 515-9.

2. Morray JP, Lynn AM, Stamm SJ, Herndon PS, Kawabori I, Stevenson JG. Hemodynamic effects of ketamine in children with congenital heart disease Anesth Analg. 1984; 63: 895-9.

3. Williams GD, Jones TK, Hanson KA, Morray JP. The hemodynamic effects of propofol in children with congenital heart disease Anesth Analg.1999; 89:1411-6.

4. Ulgey A, Aksu R, Bicer C, Akin A, Altuntas R et al. Is the addition of dexmedetomidine to a ketamine-propofol combination in pediatric cardiac catheterization sedation useful? Pediatr Cardiol.2012; 33:770-4.

5.Akin A, Esmaoglu A, Guler G, Demircioglu R, Narin $\mathrm{N}$, Boyaci A. Propofol and propofol - ketamine in pediatric patients undergoing cardiac catheterization. Pediatr Cardiol. 2005;26: 553-7. 
6. Jobeir A, Galal MO, Bulbul ZR, Solymar L, Darwish A, Schmaltz AA. Use of low-dose ketamine and/or midazolam for pediatric cardiac catheterizationls an anesthesiologist needed? Pediatr Cardiol. 2003; 24: 236-43.

7. Bernard PA, Ballard H, Schneider D.Current approaches to pediatric heart catheterizations. Pediatr Rep. 2011; 3:23.

8. Kogan A, Efrat R, Katz J. Propofol-ketamine mixture for anesthesia in pediatric patients undergoing cardiac catheterization $\mathrm{J}$ Cardiothorac Vasc Anesth. 2003; 17:691-3.

9. D.J. Steward. A simplified scoring system for the post-operative recovery room.Can Anaesth Soc J. 1975; 22:111-3.

10. Ilies $C$, Kiskalt $H$, Siedenhans $D$, Meybohm $P$, Steinfath $M$, Bein B, Hanss R. Detection of hypotension during Caesarean section with continuous non-invasive arterial pressure device or intermittent oscillometric arterial pressure measurement. Br J Anaesth. 2012; 224:1-7.

11. Malik M, Malik V, Chauhan S, Dhawan N, Kir U. Ketamine-etomidate for children undergoing cardiac catheterization. Asian Cardiovasc Thorac Ann. 2011;19:143-8.

12. Pai $A$, Heining $M$. Continuing Education in Anaesthesia, Critical Care \& Pain. 2007; 7:59-63.

13. Singh A, Girotra S, Mehta Y, Radhakrishnan S, Shrivastava S. Total intravenous anesthesia with ketamine for pediatric interventional cardiac procedures. J Cardiothorac Vasc Anesth. 2000; 14:36-9.

14. Slonim, Anthony D. Ognibene, Frederick P. Sedation for pediatric procedures, using ketamine and midazolam, in a primarily adult intensive care unit: A retrospective evaluation.Crit Care Med. 1998; 26:1900-4.

15. Reves JG, Glass PSA, Lubarsky DA. Nonbarbiturate intravenous anesthetics R.D. Miller (Ed.), Anesthesia, Churchill Livingstone, New York, NY 1994: 247-89.
16. Wheeler DS, Vaux KK, Ponaman ML. The safe and effective use of propofol sedation in children undergoing diagnostic and therapeutic proceduresExperience in a pediatric ICU and a review of the literature. Pediatr Emerg Care.2003; 19: 385-92.

17. Gozal D, Rein AJ, Nir A. Propofol does not modify the hemodynamic status of children with intracardiac shunts undergoing cardiac catheterization. Pediatr Cardiol. 2001; 22: 488-90.

18. Miner JR, Gray RO, Bahr J, Patel R, McGill JW. Randomized Clinical Trial of Propofol Versus Ketamine for Procedural Sedation in the Emergency Department. Academic Emergency Medicine. 2010; 17:604-11.

19. Munoz R, Berry D. Dexmedetomidine:promising drug for pediatric sedation? Pediatr Crit Care Med 2005; 6: 493-4.

20. De-Wolf AM, Fragen RJ, Avram MJ, Fitzgerald PC, Rahimi-Danesh F. The pharmacokinetics of dexmedetomidine in volunteers with severe renal impairment. Anesth Analg 2001; 93:1205-9.

21. Dyck JB, Maze M, Haack C, Azarnoff DL, Vuorilehto L, Shafer SL. The pharmacokinetics and hemodynamic effects of intravenous and intramuscular dexmedetomidine hydrochloride in adult human volunteers. Anesthesiology 1993; 78:813-20.

22. Marcia L. Buck. Dexmedetomidine Use in Pediatric Intensive Care and Procedural Sedation, Pharm D. J Pediatr Pharmacol Ther. 2010; 15:17-29.

23. Lebovic S, Reich DL, Steinberg LG, Vela FP, Silvay G. Comparison of propofol versus ketamine for anesthesia in pediatric patients undergoing cardiac catheterization Anesth Analg.1992;74: 490-4.

24. Wheeler DS, Vaux KK, Ponaman ML. The safe and effective use of propofol sedation in children undergoing diagnostic and therapeutic proceduresExperience in a pediatric ICU and a review of the literature. Pediatr Emerg Care.2003; 19: 385-92. 